Journal of Research in Interprofessional

Practice and

Education

Vol. 4.1

June 2014
Journal of Research in Interprofessional Practice and Education (JRIPE)

Vol. 4.1

(c) 2014

Corresponding author: Daniel Allen. Email: íllend@edgehill.ac.uki!

\section{Becoming a Nursing and Social Work Student: An Interpretive Phenomenological Analysis of Interprofessional Education}

\author{
Daniel Christopher Allen, PhD, MRes, BA (Hons); Tracey Baker, MA, \\ BSc, PGCE; \& David Leonard Rootes, MSc, BSc, PGCE
}

\begin{abstract}
Background: The call for interprofessional nursing and social work education in the United Kingdom has led to the development of a singularly integrated nursing and social work degree. Although evidence exists to highlight the impact of this degree in practice, details of the experience of interprofessional nursing and social work education have not been studied in equal depth.

Methods and Findings: Guided by the tenets of interpretive phenomenological analysis, six students who had recently completed the first year of a nursing and social work degree were asked to describe their experiences of interprofessional education. The dominant theme that emerged from analysis highlighted the importance of providing students with a bespoke curriculum, which could communicate their full and inclusive integration. Where this was not achieved, students explained that they could become confused by increased workloads and a sense of separatism.

Conclusions: When combining nursing and social work into a single degree, pedagogic strategies must be confidently prepared to deliver a specific interprofessional nursing and social work curriculum. Above all, this curriculum must demonstrate an integrated philosophy and distinctive orientation to inclusive interprofessional education.

Keywords: Student voice; Interprofessional education; Nursing and social work; Integration; Curriculum; Experience; Inclusion; Higher education
\end{abstract}

\section{Introduction}

Professional regulatory concordats in the United Kingdom constantly reiterate the need to increase the focus on interprofessional education in nursing and social work [1-2]. In a continuing effort to shift away from separatism-literally the distinct delivery of health and social work education as detached functions [3] - educational standards seek to deliver an "integrated agenda," as it is frequently cited, as an essential component in attaining a more efficient, effective, and augmented public service [4-8].

The importance of interprofessional education is reflected in the recommendations that nursing and social work education should be underpinned by a curriculum that values effective multiagency collaboration [9-11]. However, although this philosophy has gained particular impetus within contemporary discourse (see, for example, [12]), the pedagogy, curriculum, and assessment of interprofessional education are not new phenomena. Since 1988, for instance, the focus on a "collaborative movement" [13] has paved the way toward the development of a combined nursing and social work (NSW) degree, which has been successfully implemented in the UK by a number of educational institutions. 
2

Becoming a Nursing and Social Work Student: An Interpretive Phenomenological Analysis of Interprofessional Education

Allen, Baker, \& Rootes

Journal of Research in Interprofessional Practice and Education

Vol. 4.1

June 2014
Incorporating social policy recommendations with international developments such as those reported by Schneiderman et al. [14], a number of higher-education institutions (HEIs) in the United Kingdom have responded to the call for more effective interprofessional education with creativity and innovation [15]. Building on an approach that sees nursing and social work being taught within one integrated three-year undergraduate program, these HEIs have taken into account the fact that nurses and social workers play a crucial role in enabling successful outcomes [7]. Hence, the integration of nursing and social work education into one nationally recognized qualification responds to recommendations that social policy and consultation forums so frequently endorse [16-17].

The HEIs that have taken the step to combine nursing and social work in this way do so with the aim and ambition of creating a new type of worker who is able to deliver both nursing and social work services in the praxis of their professional autonomy [18]. However, ensuring that this objective is realized is complicated. One of the core problems to overcome is the very scale of organizational change that is required. The evidence cited by Schneiderman et al. [14] for the success of integrated nurse social work education is far from comprehensive. By contrast, other research [18] has linked the difficulties of implementing some key tenets of interprofessional education - in this case, separate professional regulatory standardswith those external forces that serve to determine separatist professional cultures and pedagogical ideologies. Indeed, although the integrated education of nurses and social workers may well enhance the lives of people who receive services $[7,19]$, separatism between nursing and social work can seriously undermine the spirit of integrated education [20], and, as Lymbery [21] points out, create professional-managerialist conflict. For Cleak \& Williamson [22] these collective concerns represent a longstanding problem, deriving from the need to maintain detached professional identities through territorial behaviours that become manifest through particular educational standards [1-2].

Arguably, as long as professional conflict remains, the full range of opportunities for integrated NSW education will be constrained. Summarizing research conducted in America, McLaughlin [23] and Cower [24] imply that HEIs will almost certainly struggle to achieve integrated NSW education when individual nursing and social work departments experience difficulty in accepting and embracing the fusion of both. For Schneiderman et al. [14], separate professional identities can create an "us and them" culture, which can then lead to conflicting opinions. Any potential for conflict could then question the value of interprofessional education, including how it should or should not be achieved. Where adversarial interprofessional relationships exist, nursing and social work departments can reach an impasse, reinforced by inflexible and defensive territorial paradigms, which can then bar the pathway to the recommended "integrated agenda" [16].

Although these organizational concerns are significant in relation to the implementation of a single NSW degree, little is known about how the experience of interprofessional NSW education is perceived by the student. Without any firm evidence regarding the student experience, the claim that the ambition to combine 
3

Becoming a Nursing and Social Work Student: An Interpretive Phenomenological Analysis of Interprofessional Education

Allen, Baker, \& Rootes

Journal of Research in Interprofessional Practice and Education

Vol. 4.1

June 2014 nursing and social work education could be prevented by professional conflict is difficult to substantiate. Consequently, it is important to outline the implications for interprofessional NSW education and practice.

Responding to this position, this article provides an opening dialogue to consider the student experience in further detail. By reporting on the first-stage findings of a four-year longitudinal study, this article examines a range of first-year undergraduate student experiences. It concludes that although much contested professional territory remains to be resolved, the integrated NSW degree may have a significant part to play in the "integrated agenda" [4-8]. However, the opportunities for a successful interprofessional collaborative movement within HEIs are far from guaranteed.

\section{Method}

Underpinned by the philosophical assumptions of interpretive phenomenological analysis (IPA) [25], the primary goal of this study was to develop some understanding of the way in which first-year degree students perceived and made sense of their experiences of interprofessional NSW education. IPA was chosen as the most appropriate methodology, as it provided the study with the opportunity to focus on lived experience. In line with the overarching strategy, a semi-structured research schedule comprising 11 open-ended questions was developed. Used as an aide memoir to facilitate a guided conversation, each question was designed to focus on the depth and detail of responses given toward the individual observation, perception, and interpretation of interprofessional NSW education. Ethical approval was obtained from the Faculty of Health and Social Care ethics committee at the authors' institution.

A cohort of students $(N=17)$ who had completed the first year of their interprofessional NSW undergraduate degree program were selected from a university in the UK. From this cohort, six students agreed to participate in the study. This sample consisted of five female students and one male student. Once consent was obtained, each student was interviewed face to face and on a one-to-one basis by a research assistant who was employed as an independent member of the research team. Interviews were conducted in a quiet location at the university at a time convenient for the student. All interviews were recorded on a digital Dictaphone and transcribed verbatim.

Transcripts were analysed using a hermeneutic analysis method [26]. Each script was analysed individually by each member of the interprofessional research team. Once all transcripts had been analysed, the research team convened to negotiate, develop, chart, and map the way in which individual themes gathered together. This process required members of the research team to reflect on their own interpretations before debating and agreeing on the connections that were identified through the analytical process. This included identifying themes that were most powerful, and those that illuminated different cases for each person. Following hermeneutic analysis and thematic coding, an online discussion was facilitated with each student who took part in the study so that they could provide feedback on the preliminary findings. This approach, known as member checking [27], enabled the students to 
4

Becoming a Nursing and Social Work Student: An Interpretive Phenomenological Analysis of Interprofessional Education

Allen, Baker, \& Rootes

Journal of Research in Interprofessional Practice and Education

Vol. 4.1

June 2014 check and add comments or new perspectives so that the themes the research team outlined could be clarified and developed for improved accuracy.

\section{Results}

In line with the theoretical framework of IPA, the testimonies presented in this article are discrete so that the interpretative account provided can represent a close reading of what students said [25]. As such, the student voice is presented without reference to extant literature. Later, in the discussion section, the register will change so that these experiences can be placed within the wider context of interprofessional nursing and social work education literature.

\section{Feeling like a number}

Students explained that the first year of their integrated NSW degree had been delivered within a common foundation program. Specifically, this required them to attend lectures that were delivered to larger cohorts of children's nurses, learning disability nurses, adult nurses, and mental health nurses. Given the diverse range of student nurses, each student who took part in this study explained that the content of each lecture could only extend to include the specific fields that were present. This meant that within the nursing lectures, social work was not obviously represented nor included.

The students explained that the way the common foundation program was organized meant that in order to learn about social work, they each had to attend additional smaller lectures that were delivered specifically to their small group. Because of this arrangement, a divide between nursing and social work education was created. Each student explained that rather than receiving integrated NSW education in one classroom, nursing and social work were being taught separately. Although nursing and social work education was being delivered, the perceived partitioning of each began to create the impression that interprofessional NSW study required each student to work twice as hard than if they had chosen to study nursing or social work separately:

When we were in university, just the nursing students, or just the social work students, would be in for two-and-a-half days, maybe, a week, and the rest of the week they are doing their studying and the extra work that they need to do. We were in back-to-back lectures, Monday to Friday, nine until five, five days a week. Full on like. (Interview 1)

The experience of attending large-group nursing lectures for two-and-a-half days, and then attending smaller-group lectures for social work on the remaining days, was described as being both advantageous and detrimental to the overall learning experience. Whole cohort lectures, which addressed the fundamental aspects of nursing, for example, were seen to enable a deeper understanding of nursing. Attending supplementary small-group social work lectures was perceived to enable a deeper understanding of social work: 
Becoming a Nursing and Social Work Student: An Interpretive Phenomenological Analysis of Interprofessional Education

Allen, Baker, \& Rootes

Journal of Research in Interprofessional Practice and Education

Vol. 4.1

June 2014

\section{Journal of Research in Interprofessional Practice and Education}

In our nursing, we have had theory lessons and we have had practical lessons. Our theory lessons were about anatomy and physiology, all the theory to apply to the practical, so like CPR (cardiopulmonary resuscitation), measuring blood pressure, administering medication, giving injections. And then we had our social work lessons where we've been doing about safeguarding, confidentiality, anti-discrimination, and evidence-based practice. (Interview 6)

Although the opportunity for this type of "dual" learning enabled a developing awareness of the rudimentary aspects of nursing and social work, the process of being taught these principles separately was seen to create a significant divide between the two. As a result, each student explained that the opportunities for a sense of integrated NSW education became harder to perceive:

When it came to the big lectures, sometimes the lectures would just focus on nursing and not even refer to social work, or just refer to us as "social worker colleagues"; they didn't seem to understand the point of what we're doing and...it kind of ostracized us from the larger group and caused confusion about what we were doing and what our role actually was. (Interview 2)

The student testimony reveals how the challenge presented by large-cohort teaching, which was already necessarily interprofessional to incorporate the separate fields of nursing, meant that it was perhaps difficult to include social work for the small group of NSW students without excluding the majority. However, the sense of confusion that ensued stemmed from the students' individual understanding that interprofessional NSW education should have emphasised a clearer focus on the process of integration.

Within our nursing modules in the first year social work was never mentioned; the fact we were [Nursing and Social Work students] was never really mentioned either. (Interview 4)

Being with other [fields of nursing] in the larger lecture theatres makes you feel that you're just still a number. (Interview 3)

By interpreting their experiences of teaching and learning in this way, it was almost as if the students became disenfranchised from their own expectations of an integrated learning journey. What is more, the teaching and learning strategy was seen to represent a methodology that was determined more by organizational systems and less by the inclusive principles of interprofessional student-centred education. This was further compounded by the pressure and anxieties created by being required to attend "back-to-back lectures, Monday to Friday, nine until five, five days a week":

There was times when I was thinking, "I don't know whether I can keep this up for three years." (Interview 1) 
6

Becoming a Nursing and Social Work Student: An Interpretive Phenomenological Analysis of Interprofessional Education

Allen, Baker, \& Rootes

Journal of Research in Interprofessional Practice and Education

Vol. 4.1

June 2014
By comparing their own experiences to the perceived workload of other students, the students who took part in this study explained how the intensity of a separate nursing and social work teaching and learning strategy began to create a sense of injustice. Rather than developing a sense of integration, the students appeared to adopt a view that the NSW program was made up of two courses, not a distinct, organized, and interprofessional one:

It's hard enough to do one degree course in three years; doing two degree courses in three years is really hard going. (Interview 3)

\section{Unity in adversity}

The experience of injustice that was reported appeared to stand as a significant barrier to the students' perception of interprofessional NSW education. However, the opportunity that emerged from this challenge began to enable the nursing and social work student group to unite with the shared sense of togetherness:

I do remember some [students] discussing their concerns about barriers that they had faced in university and in placement, but I always felt that the more we developed both individually and as a team, then we would be able to work through these difficulties. (Interview 1)

United more by the experience of uncertainty and increased workloads than the experience of efficient interprofessional education, this testimony shows how an NSW student identity began to develop. In relation to the integrated NSW educative journey, the opportunity to form this group provided an important turning point, which enabled the group to present a collective view of the frustration and sense of institutional ostracism they perceived:

Because we were all on a bit of learning curve with this, because it was a new course, the tutors and lecturers listened to us, what we were feeding back. We were all able to come into uni and say, “These are things we're coming up against here. These are the sorts of obstructions"... and they listened to what we were saying, and making plans, I think, for how the course should develop, taking into consideration our feedback. (Interview 1)

Reflecting on the opportunity to speak as part of a united group, each student indicated that she or he was able to become actively included in the university's administration system. This enabled them to become more proactively involved in the development of a more interprofessional learning strategy. By being able to talk about their experience of exclusion from separate nursing and social work lectures, the student group was able to work together and provide the catalyst for program evaluation and change. What is more, the student group enabled an approach to interprofessional NSW education so that the programme team could provide orientation sessions for faculty members who were teaching the small group lectures:

At first it was sort of, we were doing stuff, anatomy and physiology, pharmacology, and stuff like that in the big nursing group [large 
Becoming a Nursing and Social Work Student: An Interpretive Phenomenological Analysis of Interprofessional Education

Allen, Baker, \& Rootes

Journal of Research in Interprofessional Practice and Education

Vol. 4.1

June 2014

\section{Journal of Research in Interprofessional Practice and Education}

cohort], and then we were doing social work theory in the small NSW group [17 students], and they were separate. But over time I would say that the development of a smaller NSW group helped our thinking to develop to a point of integration with the two discourses, if you like. Because of this, I could start to think along the lines of a nurse and a social worker rather than a) a nurse, or b) a social worker. (Interview 1)

\section{A focus on interprofessional education}

Each student explained that the development of small interprofessional NSW lectures was effective because they could join the fundamental aspects of nursing and social work together. Because of this, students explained, their perception of integrated NSW education and their sense of belonging as NSW students also began to develop. By being taught by lecturers who were able to include nursing within the discourse of social work, and vice versa, the similarities and differences between each discipline could be advanced in a way that was not always evident within the larger nursing cohort. Although the teaching and learning opportunities provided to the large nursing cohort were reported to be effective for learning topics such as anatomy and physiology, the use of small-group teaching was reported as being significantly more useful because the students were supported to focus on the process of integrated NSW education in a more considered way:

The small NSW group lectures enabled me to see the bigger picture...the lecturers started to help us see how both nursing and social work came together. (Interview 2)

I don't feel like a social worker or a nurse; I do feel like a nurse social worker. (Interview 1)

By providing students with interprofessional education in this way, the students reported the ability to develop an integrated self-concept:

In terms of learning to think like a nurse and a social worker, particularly one of the assignments we had required us to take nursing models and social work theories and combine them together to see how they could assist in a particular case. I think that this was quite helpful because the lecturer got us into the frame of mind of thinking not just as a nurse, not just as a social worker, but bringing the two disciplines together. (Interview 2)

\section{Barriers to interprofessional practice}

Though the views presented by the students demonstrated a developing understanding of the functionality of interprofessional knowledge, at the most rudimentary level, they also showed, perhaps more importantly, a developing perception that NSW practice required an approach that could transcend stereotypical professional and educational boundaries. However, it is also noteworthy that the application of this understanding was problematized by a perceived lack of ability to apply inte- 
8

Becoming a Nursing and Social Work Student: An Interpretive Phenomenological Analysis of Interprofessional Education

Allen, Baker, \& Rootes

Journal of Research in Interprofessional Practice and Education

Vol. 4.1

June 2014 grated theory in practice. This experience became particularly apparent in response to the question that was asked to each student: "Can you tell me what it means to be a Nursing and Social Work student?"

From theory, I could probably give you an answer, but practically I couldn't because I haven't worked in a specific nurse social work placement. (Interview 6)

Representative of the whole, this brief excerpt showed how first-year students can perceive the integration of NSW practice as only literally possible in placements that can provide an interprofessional NSW placement. This observation is crucial to understanding that although each student values the advantages and nuances of interprofessional education, the principles of application may remain theoretically distant unless there is an obvious opportunity to discuss or develop these skills in practice. Although the students demonstrated a developing ability to assess situations by drawing on rudimentary nursing and social work theory, they did not always recognize the value of transferring this understanding to the situations that they were exposed to while on placement. It could therefore be argued that although the opportunities for interprofessional NSW practice may have been available for each student, they were unable to identify them as such because of an ongoing perception of the separatist context and organization of nursing and social work more generally.

\section{Discussion}

The testimonies presented in this article have shown that effective interprofessional NSW education must be able to communicate a message that students undertaking an NSW degree are valued. If this is not achieved, a sense of confusion can be developed, as the delivery of teaching and learning is seen to focus more on the organizational constraints of professional separatism and less on the focus of interprofessional education.

According to Astin's [28] theory of student involvement, the initial experiences of confusion described in this study represent a crucial factor in the overall experience of educative inclusion. At the most fundamental level, this theory argues that when students do not feel that their individual position within educational institutions is respected, they are more likely to experience strong feelings of alienation, isolation, and social exclusion. As demonstrated with this study, where alienation, isolation, and social exclusion were reported, Thomas [29] explains that some students might also be at higher risk of withdrawal.

Building on Bourdieu and Passeron's [30] notion of cultural capital and habitus, Thomas [29] argues that the most effective way to protect against these risks requires HEIs to design and maintain a high-quality student-centred teaching and learning strategy. This, she argues, is vitally important in the process of supporting students to develop a sense of belonging. At an individual level, Vallerand [31] has shown that a high-quality student-centred teaching and learning can be realized by HEIs that are able to value the students' experience and promote their perception of connect- 
9

Becoming a Nursing and Social Work Student: An Interpretive Phenomenological Analysis of Interprofessional Education

Allen, Baker, \& Rootes

Journal of Research in Interprofessional Practice and Education

Vol. 4.1

June 2014 edness to the social milieu of the institution. Although Thomas [29] argues that "belonging" is a key element of an effective teaching and learning strategy, chiefly because it is closely aligned with the concepts of academic and social engagement $[30,32]$, the specific elements required to promote it could be hard to define, not least because the opportunities needed to support a sense of belonging will vary from discipline to discipline and individual to individual. However, corresponding with Goodenow's [34] analysis of school membership among adolescents, the students who took part in this study explained that when they were not being recognized, listened to, or included, their expectation of a program of interprofessional study was undermined, thus threatening their ability to develop a sense of belonging.

By comparing the initial experiences presented in this study to the wider concerns over interprofessional working in health and social care [7], it could be argued that the initial ability to develop a perception of belonging was prevented by the exact same tensions and interdisciplinary strains that tend to define interprofessional collaboration more generally. This was reflected most strongly in the suggestion that some nursing or social work lecturers were only able to deliver lectures within the boundaries of their own professional expertise. As shown in Pietroni's [35] notion of traditional hierarchies, the perception that some lecturers avoided the opportunity to include the discourses of both nursing or social work, their commonalities, distinctive contributions, complementary paradigms, and conflicting principles, left students with a deep sense of frustration:

The information was often thrown out at us by nursing and social work lecturers without taking into consideration what we were actually doing. (Interview 2)

Within the context of integrated NSW education, this finding supports Schneiderman et al.s [14] observation that organizations must be able to carefully plan for, and include, opportunities for shared learning. In other words, university systems must be prepared to embrace the fusion of a specific, focused, and inclusive NSW curriculum. As shown in the testimonies presented above, it is not enough to expect that a nursing and social work student will be able to integrate nursing and social work or develop a sense a belonging within an interprofessional curriculum by simply attending separate nursing and social work lectures. Whereas Ramsden [36] may disagree with this observation and argue that the responsibility of any university is "to encourage students to confront different conceptions and to practice making sense for themselves," the testimonies provided in the present study clearly demonstrate that this cannot easily be achieved unless the similarities and differences between nursing and social work are introduced and explored first.

Understanding more about the anatomy and the physiology and being able [to] analyze the medical side of things in the big group has been really invaluable to me. And then coming into smaller nurse social work groups and getting to grips with the social side of things has been quite exciting for me because it has helped to join up 
10

Becoming a Nursing and Social Work Student: An Interpretive Phenomenological Analysis of Interprofessional Education

Allen, Baker, \& Rootes

Journal of Research in Interprofessional Practice and Education

Vol. 4.1

June 2014 the framework, if you like. So I feel like I am in the middle, like, of the two. (Interview 1)

On this basis, this article has shown that interprofessional NSW education requires, as far as practically possible, a joint or shared inclusive enterprise that aims to achieve the basic assumptions of Edwards et al.'s [37] theory of professional multilingualism. Although the research focus of these authors lies elsewhere, the recommendations proposed are important within the wider context of the present study because they support the notion that cultural literacy is an essential tool in the intertwinement of any form of interprofessional education [36]. Nonetheless, the inherent challenge in achieving professional multilingualism in interprofessional NSW education is reflected in the sense of confusion that each student described as they spoke about the perceived need to develop an understanding of the separate aspects of nursing and social work. Although the importance of enabling students to explore the similarities and differences between nursing and social work within the same lecture has already been made clear, each student inferred that their expectation was not to be taught how to become professionally multilingual, but instead how to speak a specific combined nursing and social work language in one. As each student recalled, where this opportunity was not obviously available, their sense of frustration became reinforced by the perception that nursing and social work were separate and that they were (unjustly) completing two separate three-year degree courses in one.

Reconciling this frustration then requires HEIs to balance curriculum design against the possibility of disjuncture or the unwitting attenuation of knowledge [38]. As nursing and social work undergraduate degrees in the UK have traditionally been taught over three years, the inherent danger in the development of an interprofessional NSW degree is then to take nursing and social work and simply attempt to combine the two. However, as this study has shown, if the act of combining professional degrees is attempted without giving due regard to interprofessional fusion and the student experience, the risks associated with withdrawal, including burnout, can be increased. This demonstrates, therefore, that although Edwards et al.s [37] theory of professional multilingualism is important, it is not a realistic option for first-year students studying in an interprofessional NSW program. As this study has revealed, presuming that students will simply make sense of nursing and social work without a clear indication of an integrated pedagogical approach is unsustainable because it does not engender a sense of belonging.

This need for a sense of belonging notwithstanding, this study does indicate that the premise of Edwards et al.'s [37] theory should hold great significance for those nurses and social workers responsible for designing and delivering interprofessional NSW education. In other words, it is the nursing and social work lecturers, practice educators, and mentors, rather than the students, who should be, or at least be prepared to become, professionally multilingual so that they can embrace and communicate the opportunity for inclusive fusion of both perspectives through effective collaboration. 
Becoming a Nursing and Social Work Student: An Interpretive Phenomenological Analysis of Interprofessional Education

Allen, Baker, \& Rootes

Journal of Research in Interprofessional Practice and Education

Vol. 4.1

June 2014

\section{Journal of Research in Interprofessional Practice and Education}

I think when you're trained in [nursing] or [social work] it's very much social work thinking or nurse thinking, and they go off the medical model or the social model, whereas with us we are being trained by the lecturers, particularly in the small NSW group, to be a nursing and social work practitioner. (Interview 4)

As this extract suggests, an effective integrated NSW curriculum is one that can be delivered by interprofessional lecturers who are able to facilitate sustainable inclusion and provide students with a real sense of belonging. Above all, this requires the university, and individual nursing and social work lecturers, to demonstrate to the student that they, and the process of transcultural and interprofessional NSW education, are important. Where this is not consistently achieved, this study has shown that some first-year students may feel apprehensive about transferring their developing understanding of interprofessional NSW education, self-concept, skills, and language into practice:

I was thinking, "Well what's was the point of putting ourselves through all of this when we might only be nurses or social workers at the end." (Interview 5)

As this testimony shows, unless interprofessional NSW education is accepted at an organizational and individual level, the opportunity to enable students to become the type of integrated specialist worker that social policy and service-user consultation so frequently demands could be lost. Therefore, if nursing and social work lecturers do determine the value of interprofessional education within the boundaries of their own separate orientations to knowledge acquisition and practice, the philosophy of an integrated NSW education could be jeopardized, along with the students' perception of the university and the course that they have committed to.

\section{Limitations}

It is important to note that this study was conducted by a research team that has had input into the design and delivery of the interprofessional NSW degree program. As such, the research team's position within this study should be recognized. To reduce bias, an independent research assistant was recruited specifically to facilitate each student interview. The research assistant had no connection to the university or the students prior to the study and was able to facilitate the entire process of student engagement, sampling, and interview independently. Although the transcripts were analysed by the interprofessional research team, an online facility was also established for member checking [27], which aimed to enable each student to comment on the accuracy of the interpretations being presented. Although passive acquiescence could have been a possibility, based on the students' relationship with the research team, it is hoped that the opportunity to promote rigour and accuracy has been realized in the presentation of results and subsequent critical discussion. It is also recognized that the small-scale nature of this study means that the views of the 
12

Becoming a Nursing and Social Work Student: An Interpretive Phenomenological Analysis of Interprofessional Education

Allen, Baker, \& Rootes

Journal of Research in Interprofessional Practice and Education

Vol. 4.1

June 2014 students cannot be taken to represent the wider experience of interprofessional NSW education. Although generalizability was not the driving aim of this study, the findings and recommendations that are presented could offer a useful, albeit preliminary, foundation for any organization planning, or reviewing, the delivery of integrated NSW education.

\section{Conclusion}

By applying the tenets of IPA and hermeneutics, this article has shown that it is essential for those responsible for teaching and supporting students to develop their own understanding of the similarities and differences between nursing and social work practice, including the complex milieu in which these operate. To be effective, educators must be prepared to become professionally multilingual so that the common, distinctive, and complementary elements between nursing and social work can be explored. It is recognized that the recommendations presented do have wider resonances in the political and economic context of nursing and social work, particularly where professional hierarchies, divides, and resource limitations exist. As such, it has been suggested that those responsible for interprofessional NSW education must not become complicit with the reinforcement of these divides or expect integration "to just happen." Instead, education structures must be flexible enough to attend to interprofessional NSW education and small-group teaching and learning with an open mind.

The first step toward success in interprofessional education requires organizations to be prepared to revise their approach to assessing, planning, implementing, and evaluating pedagogic approaches and curriculum so that equal attention is afforded to the values and perspectives of both nursing and social work. The implementation of an inclusive and specific NSW curriculum is crucial so that a shared sense of interprofessional education can be developed, even if this means accepting the development of a new NSW pedagogic approach that must necessarily be different to existing nursing and social work structures.

In light of existing interprofessional tensions, it is accepted that the recommendations presented in this article may also be difficult for some organizations to achieve and sustain. However, it is also clear that the centrality of the interprofessional NSW learning journey should never be lost to wider organizational or cultural constraints. If attention is given to the inclusion of students and the development of a specific integrated NSW curriculum, those responsible for the delivery are also responsible for interprofessional collaboration and should not expect integration to happen because students are being taught nursing and social work. As Smith [39] points out, interprofessional collaboration "must be prepared for, both strategically and at a level of practice" and, as this article has shown, this advice is equally important for HEIs looking to plan an effectively inclusive NSW curriculum. 
Becoming a Nursing and Social Work Student: An Interpretive Phenomenological Analysis of Interprofessional Education

Allen, Baker, \& Rootes

Journal of Research in Interprofessional Practice and Education

Vol. 4.1

June 2014

\section{Abbreviations}

\author{
NSW - Nursing and Social Work \\ HEIs - Higher Education Institutions \\ IPA - Interpretative Phenomenological Analysis
}

\section{References}

1. Nurse Midwifery Council. (2010). Standards for pre-registration nursing education. London: Nursing and Midwifery Council.

2. Health and Care Professions Council. (2012). Standards of proficiency for social workers in England. London: Health and Care Professions Council.

3. Maslin-Prothero, S.E., \& Bennion, A.E. (2010). Integrated team working: A literature review. International Journal of Integrated Care, 10, 1-11.

4. Leathard, A. (1994). Going inter-professional: Working together for health and welfare. London: Routledge.

5. Laming, H. (2003). The Victoria Climbié Inquiry report. London: Stationery Office.

6. Brandon, M., Belderson, P., Warren, C., Howe, D., Gardner, R. et al. (2008). Analysing child deaths and serious injury through abuse and neglect: What can we learn? A biennial analysis of serious case reviews 2003-2005. London: Department for Children, Schools, and Families.

7. Laming, H. (2009). The protection of children in England: A progress report. London: Her Majesty's Stationery Office.

8. Littlechild, B., \& Smith, R. (Eds.). (2013). Handbook for interprofessional practice in the human services. London: Pearson Education Limited.

9. Royal College of Nursing. (2006). The impact and effectiveness of inter-professional education in primary care: A RCN literature review. London: Royal College of Nursing.

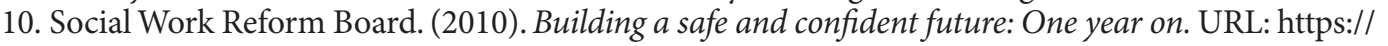

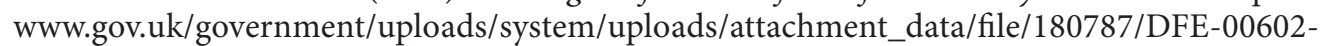
2010-1.pdf '[May 12, 2013].

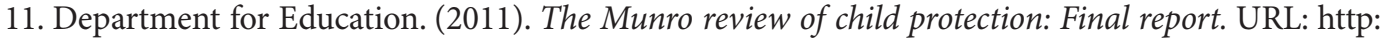

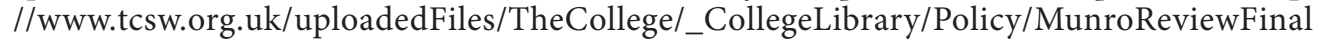
Report.pdfi'[May 12, 2013].

12. Health and Social Care Act. (2012). London: Stationery Office.

13. Barr, H., Hammick, M., Koppel, I., \& Reeves, S. (1999). Evaluating interprofessional education: Two systematic reviews for health and social care. British Educational Research Journal, 25(4), 533-544.

14. Schneiderman, J.U., Waugaman, W.R., \& Flynn, M.S. (2008). Nurse social work practitioner: A new professional for health care settings. Health and Social Work, 3(2), 149-154.

15. Sims, D. (2011). Achieving collaborative competence through interprofessional education. Lessons learned from joint training in learning disability nursing and social work. Social Work Education, 30(1), 98-112.

16. Hawkins, J.W., Veeder, N.W., \& Pearce, C.W. (1998). Nurse-social worker collaboration in managed care: A model of community case management. New York: Springer Pub Co.

17. Low, H., \& Weinstein, J. (2000). Interprofessional education. In Pearce, R. \& Weinstein, J. (Eds.), Innovative education and training for care professionals: A provider's guide. (pp. 205-20) London: Jessica Kingsley.

18. Sims, D. (2011). Reconstructing professional identity for professional and interprofessional practice: A mixed methods study of joint training programmes in learning disability nursing and social work. Journal of Interprofessional Care, 25, 265-271.

19. Aldgate, J., Jones, J., Rose, W., \& Jeffery, C. (Eds.). (2006). The developing world of the child. London: Jessica Kingsley Publishers.

20. Morris, K. (Ed.). (2008). Social work and multi-agency working. Bristol: Policy Press.

21. Lymbery, M. (2000). The retreat from professionalism: From social worker to care manager. In Malin, N. (Ed.), Professionalism, boundaries and the workplace. London: Routledge.

22. Cleak, H., \& Williamson, D. (2007). Preparing health science students for interdisciplinary professional practice. Journal of Allied Health, 36, 141-149.

23. McLaughlin, A.M. (2002). Social work's legacy: Irreconcilable differences? Clinical Social Work Journal, 30(2), 187-198. 


\section{JRIPE}

Becoming a Nursing and Social Work Student: An Interpretive Phenomenological Analysis of Interprofessional Education

Allen, Baker, \& Rootes

Journal of Research in Interprofessional Practice and Education

Vol. 4.1

June 2014

\section{Journal of Research in Interprofessional Practice and Education}

24. Cower, C.D. (2003). The values of the research university should be maximized to strengthen social work education. Journal of Social Work Education, 39, 43-47.

25. Smith, J.A., Flowers, B., \& Larkin, M. (2009). Doing interpretive phenomenological analysis. London: Sage.

26. Palmer, R. E. (1969). Hermeneutics. Illinois: Northwest University Press

27. Smith, R. (2009). Doing social work research. Reddich: Open University Press.

28. Astin, A.W. (1984). Student involvement: A developmental theory for higher education. Journal of College Student Personnel, 25, 297-308.

29. Thomas, L. (2012). Building student engagement and belonging in higher education at a time of change: Final report from the What Works? Student Retention \& Success programme. London: Paul Hamlyn Foundation.

30. Bourdieu, P., \& Passeron, J. (1977). Reproduction in education, society, and culture, 2nd edition (R. Nice, Trans.). London: Sage Publications.

31. Vallerand, R.J. (1997). Toward a hierarchical model of intrinsic and extrinsic motivation. In Zanna, M.P. (Ed.), Advances in experimental social psychology, (pp. 271-360). New York: Academic Press.

32. Davies, R., \& Elias, P. (2003). Dropping out: A study of early leavers from higher education. Department for Education and Skills Research Report 386. London: Her Majesty's Stationery Office.

33. Trowler, V., \& Trowler, P. (2010). Student engagement evidence summary. York: Higher Education Academy.

34. Goodenow, C. (1993). Classroom belonging among early adolescent students: Relationships to motivation and achievement. Journal of Early Adolescence, 13(1), 21-43.

35. Pietroni, P.C. (1994). Interprofessional teamwork: Its history and developments in hospitals, general practice and community care (UK). In: Leathard, A. (Ed.), Going interprofessional: Working together for health and welfare. London, Routledge.

36. Ramsden, P. (2003). Learning to teach in higher education, 2nd edition. London: Routledge Falmer.

37. Edwards, A., Daniels, H., Gallagher, T., Leadbetter, J., \& Warmington, P. (Eds.). (2009). Improving inter-professional collaborations: Multi-agency working for children's wellbeing. New York: Routledge.

38. McCroskey, J. (1998). Remaking professional and interprofessional education. In McCroskey, J. \& Einbiner, S.D. (Eds.), Universities and communities: Remaking professional and interprofessional education for the next century. (pp. 3-23). Wesport: Praeger.

39. Smith, R. (2013). Working together: Why it's important and why it's difficult. In Littlechild, B., \& Smith, R. (Eds.), Handbook for interprofessional practice in the human services. London: Pearson Education Limited. 